\title{
Phenomenology as a Methodology for Scholarship of Teaching and Learning Research
}

\section{ABSTRACT}

The Scholarship of Teaching and Learning (SoTL) is a rich forum where scholars from different fields and philosophical orientations find space to share their research on teaching and learning in higher education. Within this article, we share our individual and collective experiences of why we perceive phenomenology as a methodology well suited for a broad range of SoTL purposes. Phenomenology is a research approach that focuses on describing the common meaning of the lived experience of several individuals about a particular phenomenon. We discuss how phenomenology has informed our own SoTL research projects, exploring the experiences of faculty and undergraduates in higher education. We highlight the challenges and affordances that emerged from our use of this methodology. Phenomenology has motivated us to tell our stories of SoTL research and within those, to share the stories that faculty and students shared.

\section{KEYWORDS}

phenomenology, Scholarship of Teaching and Learning, higher education, methodology, lived experience

\section{INTRODUCTION}

The Scholarship of Teaching and Learning (SoTL) is a distinctive form of research within the broad scope of many different disciplines and interdisciplinary approaches (Hubball \& Clarke, 2010). As such, the scholars who engage in this type of research bring to it their own epistemological and methodological frameworks, which can lead to debate about how best to conduct SoTL research (Huber, 2010). The debate over these frameworks delineate two camps (Huber, 2010); those who emphasize SoTL's affinity with conventional research and those who use the "big tent" to cover a wide range of work in greater or lesser degrees of polish. In other words, SoTL scholars may choose to conduct their research according to the conventions of their discipline (e.g. as a biologist or sociologist) or within the conventions of SoTL (e.g., as an educator in biology).

It is this lack of an authoritative approach to SoTL research that could lead critics to question the cohesion of SoTL as a research field. If we are to encourage the 'big tent', then it must be a rich forum where scholars from various fields, interests, and philosophical orientations find space and share their research with similar guiding principles. Acknowledging and adopting various theoretical approaches will allow our work to change the landscape of teaching and learning at the classroom, institutional, national, or international level. Therefore, we suggest that SoTL researchers drive their 
inquiry with focused research questions, scholarship that is literature informed and methodologically rigorous, and disseminated for peer review (Hubball, Clarke, Webb, \& Johnson, 2015).

Within this article, we share our individual and collective experiences of adopting interpretive phenomenology, a methodology that we perceive as well suited for a broad range of SoTL purposes. We do not claim to be methodological experts, but want to share how phenomenology offered a useful methodological framework for our SoTL research projects that investigated both faculty and student experiences in higher education. In order to build an understanding about the use of phenomenology and phenomenological methods in SoTL projects, we first provide a brief overview of our different research projects. We then turn the analytical lens on phenomenology to holistically explore the challenges and benefits of its adoption in SoTL research. Despite the different contexts and participants in each of our projects, phenomenology provided a means for answering the research questions driving our work.

\section{METHODOLOGIES IN SOTL}

SoTL research is conducted in different disciplines and contexts and with many different approaches. Hutchings (2007) highlights the tension in SoTL between theory and practice; with the ultimate application in the classroom. There is so much diversity by personal approach, department, and Faculty that it is challenging to create links across SoTL through the disciplines, but she believes that looking for common themes and aims is essential to continuing the work of SoTL. Critiques of SoTL tend to focus on the localized, classroom-based research, the North American context, and the lack of focus on institutional context. This is supported by Stierer and Antoniou (2004), who note that much of the pedagogic research being conducted in higher education is done by practitioners with disciplinary and research background in areas other than education. Parker (2009) argues that SoTL needs more educational theory to legitimize its application in an educational space, while Hutchings (2007) and Kreber (2007) bring attention to the integration of research, practice, and teaching of SoTL scholars within and across many disciplines. This theoretical debate exposes a fundamental challenge in SoTL research; in order to avoid controversy, researchers often focus on methods rather than methodologies.

Methodology has been defined as the logic and theoretical perspective embedded within a research project, whereas methods are the specific techniques used for investigation and assessment (Bogdan \& Biklen, 1998). Anderson, Nashon, and Thomas (2009) indicate that methodology is not only the methods one uses to conduct research, but involves the "research design, including its foundations, assumptions, limitations, and characteristic procedures and outcomes" (p. 182). Boekaerts and Corno (2005) echo this description and emphasize the need for researchers to be more willing to discuss how epistemologies, conceptual models, assessment tools, and research design are conceptualized within a given research project.

As a unique form of research (Hubball \& Clarke, 2010), SoTL research is within the "broad umbrella for many different disciplines and interdisciplinary approaches" (p. 8). It is impossible to prescribe quantitative or qualitative methods, as the research will be driven by the nature of the research question. Therefore, Danielson (2012) proposes that we consider SoTL as a methodology, "a philosophical study of plurality of methods" (Watzlawick, Weakland, \& Fisch, 1974, p. 8, as cited in Danielson, 2012, p. 3). The scholarship of teaching and learning invites scholars from various disciplinary backgrounds to engage with methodologies and methods that best answer their research questions, which may or may not align with their disciplinary epistemologies or methodologies. It is 
critical for SoTL scholars to question and clarify their positionalities in order to ensure they are maintaining rigorous SoTL work. The scholarship of teaching and learning builds on scholarly approaches (e.g., grounded in appropriate higher education literature, reflection, evidence-based monitoring, and improvement), with greater attention placed on grounding the research in scholarly literature, methodological rigour, and dissemination in peer reviewed contexts, such as academic journals and conference presentations (Hubball, et al., 2015, p. 3-4). Therefore, SoTL research requires adaptable, flexible methodologies and reflective, broad-minded researchers.

\section{PHENOMENOLOGY}

Qualitative research situates the researcher as an observer and interpreter of things in their natural setting, while attempting to make sense of or interpret phenomena within multiple, locally constructed realities (Denzin \& Lincoln, 2011). As a result, knowledge is not universally true but an understanding based on what we have been able to glean through observation and interpretation. In phenomenology, the emphasis is on the world as lived by a person, not the world or reality as something separate from the person (Laverty, 2003). As described by Moran (2000), phenomenology is "a practice rather than a system...the attempt to get to the truth of matters, to describe phenomena, in the broadest sense as whatever appears in the manner in which it appears, that is as it manifests itself to consciousness, to the experiencer" (p. 4).

We live through or perform conscious experiences, which differentiates them from other observed or engaged phenomena (Smith, 2006). The meaning experiences have in the first person point of view demonstrates the significance of objects and events as they arise and we are aware of them. Interpretive phenomenology describes things as they are, in the way that participants experience them (Moran, 2000). In this way, phenomenology aligns with the hermeneutic tradition, taking the study of phenomena beyond description of core concepts to look for meanings embedded in human experience rather than what they consciously know. The focus of this type of phenomenological inquiry is the individual's subjective experience, and understanding of the individual's world becomes the focus of inquiry (van Manen, 1997). Interpretive phenomenology assumes that individuals make choices, but they are circumscribed by the specific conditions of their everyday life, known as situated freedom. This contextual understanding of experience suggests that description of phenomena without interpretation is impossible (van Manen, 1997). Therefore, the lived phenomena is the foci of the research and the reality and meaning of this phenomenon is embedded within the conscious experience of an individual and the researcher.

\section{Figure 1. Phenomenological interpretation}

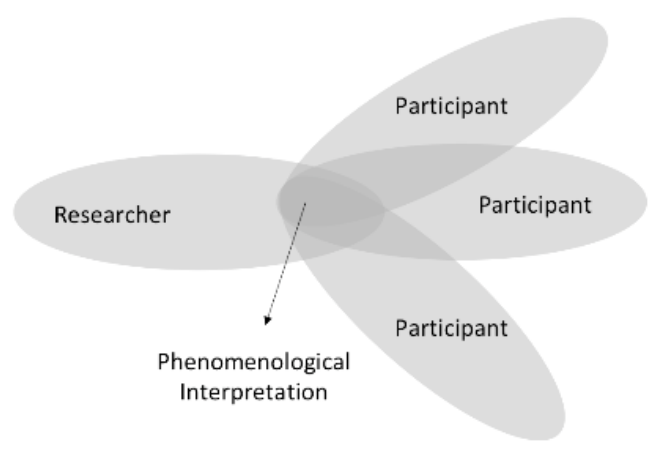


Figure 1 illustrates the intersection point at which the researcher develops the phenomenological interpretation. The role of the researcher is to use their expert knowledge to guide the inquiry and make it meaningful. Rather than collecting individual essences from each lived experience as in descriptive phenomenology, the commonalities and differences in the individual subjective experiences contribute to the description of the meanings that participants make and how those meanings influence their choices. Interpretive phenomenology attends to the unique experience of each participant within the experience of the same phenomena (Laverty, 2003; van Manen, 1997).

As an approach to research, phenomenological inquiry is characterized by

- emphasis on the phenomenon as a single idea or concept;

- emphasis on broad philosophical assumptions;

- data collection typically done through interviews;

- data analysis that moves from narrow units to broad themes; and

- culminates in a description of the essence of the phenomenon (Creswell, 2013).

Rather than focus on a particular cohort (case study), develop theory (grounded theory), focus on the individual (narrative inquiry) or the shared culture of a group (ethnography), phenomenological inquiry is a research approach that focuses on describing the common meaning for several individuals of their lived experience of a phenomenon (Creswell, 2013).

By turning attention to and investigating tacit understandings, phenomenological inquiry seeks out the "novel features of familiar situations" (Giorgi \& Giorgi, 2003, p. 249) through the experience of participants. These experiences are most commonly collected via in-depth interviews, with the interpretation focusing on statements, meanings, and descriptions related to the phenomena of interest (Creswell \& Poth, 2018). In these studies, the purpose of phenomenological inquiry is not to solve problems, but to provide a rich description of a particular phenomena and to come to a better understanding of what it means to learn. When focused on SoTL research questions, phenomenology focuses on the conscious experiences of the participants and recognizes the co-construction of knowledge.

\section{PHENOMENOLOGY IN ACTION}

Below, we each discuss how phenomenology informed our research projects and the challenges and affordances of adopting this methodology. The goal of these studies was to understand in detail the experiences of a particular group of participants. While general themes were drawn from the corpus of data, a focus on the particular is commensurate with our belief that every participant's account represents a unique truth, as each of their experiences is embedded in their background and context. Therefore, the objective of our research was not to determine one universal meaning of the phenomena, but to attend to the unique experiences of each participant. These research projects represent a coconstruction of our interpretations with the lived experiences of the participants.

\section{Project A}

This research study explored the lived experience of educational leaders in a research-intensive context as they engage in the scholarship of teaching and learning in the International Program for the Scholarship of Educational Leadership: UBC Certificate on Curriculum and Pedagogy in Higher Education (UBC SoTL Leadership Program). For this project, van Manen's interpretive phenomenology (1997) was adopted as the primary methodology to explore threshold concepts (Meyer 
\& Land, 2003; 2005; 2006) in SoTL. The research questions asked were, for institution-level and faculty-level educational leaders at University of British Columbia (UBC), a research-intensive university,

- What are the nature and substance of threshold concepts in SoTL?

- What enhances or constrains their ability to navigate threshold concepts in SoTL?

The primary method of data collection was in-depth, semi-structured interviews conducted twice during the program. The interview protocol focused on the participants' reflections of their conscious experience in the UBC SoTL Leadership Program. In this case, the purpose of the phenomenological inquiry was not to solve problems in learning SoTL, but to come to a better understanding of how faculty learn to do SoTL (Webb, 2015).

As an educational leader and SoTL instructor, my experience informed the research questions and guided my inquiry to make it meaningful (Lopez \& Willis, 2004). It is impossible for me to put aside my previous knowledge, as that knowledge is central to how I know the world (van Manen, 1997). Instead, I reflected on the tacit knowledge, beliefs, and assumptions that I brought to the study. It was important for me to consciously determine how and in what way my personal understanding would be introduced. Rather than bracket out my experience, my presuppositions and knowledge helped to guide the inquiry and meaningfully describe the phenomena (Lopez \& Willis, 2004). For example, my knowledge of the background literature is what lead to identifying gaps in the knowledge and how the inquiry should proceed. My experiences as a UBC SoTL Leadership Program participant and member of the instructional team have led me to believe that there are conceptual barriers to learning SoTL.

Interpretive phenomenological research, despite having similar underlying concepts and principles, provides no detailed procedures for the researcher to follow. However, van Manen (1997) outlines six steps that informed the research procedure of this study (see figure. 2). These steps are (1) turning to a phenomenon of interest; (2) investigating experience as lived rather than conceptualized; (3) reflecting on the essential themes; (4) describing the phenomenon through writing and re-writing; (5) maintaining a focus on the phenomenon; and (6) balancing the research by considering the parts and the whole. While the research did not follow the steps in a linear process, each was important in the collection and analysis of the corpus of data.

Figure 2. Six steps in phenomenological inquiry (van Manen, 1997)

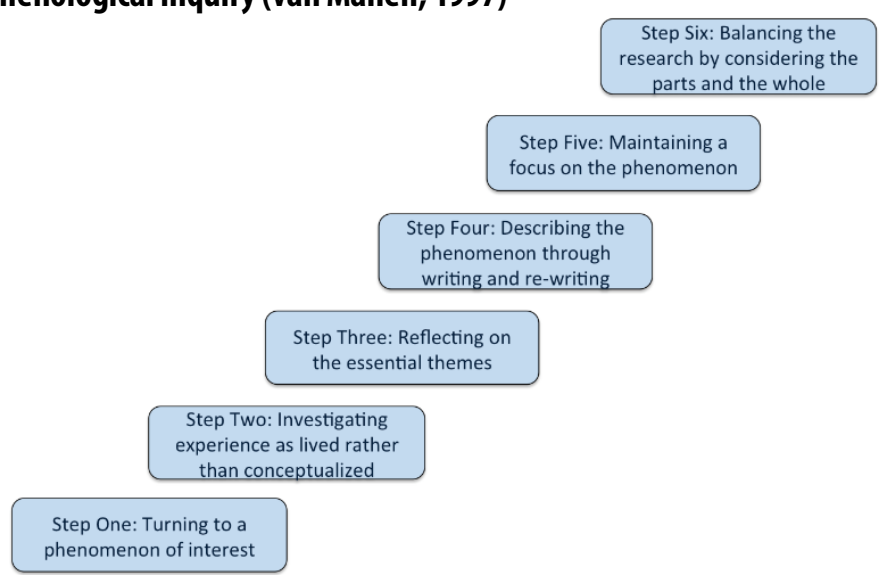


As shown in figure 2, the layering of the data collection and analysis methods means that there is no unidirectional set of steps. Instead the process is based around iterative collection, reflection, and analysis. Ongoing data collection and interaction with the data allowed for movement between the different steps in van Manen's (1997) analysis. What makes van Manen's process of data analysis particularly fitting for this project was the ability to move up and down along the staircase as new data is collected and themes emerge and coalesce. This was an appropriate means to address the research question while generating rich description of the phenomenon under study.

\section{Benefits}

Phenomenology offered significant benefits to the design and implementation of this research. The strength of the interpretive phenomenological approach is that it focuses attention on previously unknown areas and can be used to explore and illuminate the meaning of a phenomenon when little is known (van Manen, 1997). Therefore, I could explore the nature and substance of the potential threshold concepts in SoTL, which had not been done before.

As an educational leader and member of the instructional team, I occupied both an insider and outsider role in the research. As a result, the interviewees could use a shared language and conceptual understanding to describe a locally constructed reality.

At the same time, reflective of the research questions, the objective of this research project was not to determine one universal meaning of the phenomena of threshold concepts in SoTL, but instead to seek out the commonalities and differences in the individual subjective experiences that contribute to the description that participants make of their experience. In this way, interpretive phenomenological inquiry is "responsive to the phenomena being explored" (Dall'Alba, 2009) as I looked for meanings embedded in the participants' experience in order to make decisions regarding the research questions.

\section{Challenges}

In this research, there are limitations to using a phenomenological research approach. The intent of this study was to highlight one particular interpretation of the lived experience of a phenomenon. The findings in this study represent a co-construction of my interpretations and the lived experience of the participants, and therefore invite further exploration of the meaning of the phenomenon of threshold concepts in SoTL (Moran, 2013). However, this project was based predominantly on interviews. It is necessary that the participants are able to clearly articulate their lived experience in the interview. Even then, the scope of the study may miss influential factors that led up to the experience of the concomitant factors associated with the experience. Therefore, the findings and conclusions are highly influenced by the study population and the time frame of the data collection.

While measures were taken to maximize credibility and dependability, it is inevitable that this study's findings are influenced by the fact that the participants were volunteers and the fact that the researcher was a member of the instructional team. As well, it is possible that those who desired to participate were somehow different than those who elected not to participate. Ultimately, the study participants were interested in, and comfortable with, sharing their experiences. It is possible that some people elected not to participate as they had had a negative experience or did not consider their experience noteworthy. 


\section{Project B}

The second project highlights how phenomenology and particularly, phenomenological interviews supported a research project exploring undergraduate students' "lived experience" (Adams \& van Manen, 2008) of metacognitive learning in a large, introductory science class (Welsh, 2015). Flavell (1979) refers to metacognitive experiences as metacognitive knowledge that has entered consciousness; a cognitive realization that the learner does or does not know how to approach a learning task. Learners use their knowledge of these metacognitive experiences to develop skills to plan, monitor, control, and evaluate their learning (Welsh, 2015). Therefore, learners consciously experience metacognition as a phenomena and describe their personal account of developing metacognitive skills.

While an interpretive case study methodology (Creswell, 2009; Stake, 1995; Yin, 2009) was adopted for this project to understand student learning in a given cohort, interpretive phenomenology provided a necessary framework and methods (Creswell, 2013; Østergaard, Dahlin, \& Hugo, 2008) for particular data collection methods and analysis. This interpretive case study explored the following research questions:

- What catalysts (activities, events, and/or interactions) do students perceive as influential to their metacognitive change in a large, introductory science course?

- What aspects/characteristics of these catalysts do students perceive as influential to their metacognitive change?

- What do students perceive as the barriers and enhancers to their metacognitive change and how do these manifest during science study discourse?

Similarly to the aforementioned project, I was cognizant of how my own assumptions and biases influenced the research project. Creswell (2009) indicates that researchers must articulate and be aware that

$[t]$ heir own backgrounds shape their interpretation, and they position themselves in the research to acknowledge how their interpretation flows from their personal, cultural, and historical experiences. The researcher's intent is to make sense of (or interpret) the meanings others have about the world. ( $\mathrm{p}$. 8)

As such, I acknowledge that my interpretations of student experiences were a result of my engagement and interactions with them during the in-depth interviews. As the researcher within this setting, I "do not claim that [my] knowledge claim is a complete or the right one, but that it is a sensible interpretation of the situation" (Treagust, Won, \& Duit, 2014, p. 7).

As mentioned previously, the primary methodology for this project was interpretive case study, a research approach that seeks to understand complex bounded social phenomena through meaningful representations of real-life events (Stake, 1995; Yin, 2009). The strength of this approach is its ability to gather and triangulate a variety of rich data collected via a combination of quantitative and/or qualitative methods (Yin, 2009). Adopting this methodology allowed me to conduct a "naturalistic study of teaching and learning in one setting" (Stake, 1997, p. 257) and to provide a more holistic picture of student experiences within this particular introductory science course. 
Within this research, phenomenological in-depth interviews (Adams \& van Manen, 2008; Creswell, 2013; Østergaard et al., 2008) were selected to develop meaning from understanding through the exploration of the experiences and reflections of a subset of students in the course. A case study approach often adopts phenomenological principles as the case "involves intensive and detailed study of one individual or of a group as an entity, through observation, self- reports, and any other means" (Mertens, 1998, p. 166). As a researcher, I was interested in exploring both science students' lived experiences (Adams \& van Manen, 2008; Østergaard et al., 2008) and how they interact with or experience a particular phenomena (metacognition) within a given context or culture (Creswell, 2013; Treagust et al., 2014).

For this study, data collection methods included a metacognitive survey instrument, classroom observations, student reflections, and in-depth interviews. Each method provided a window into the students' perceptions of how particular activities, events, and/or interactions (both inside and outside of the class) affected their metacognition and overall learning experiences. The in-depth, phenomenological interviews however, provided the opportunity to engage on a personal level with students and to allow space for them to elaborate and reflect upon their earlier performance and learning within the course. The embeddedness of this phenomenological method within this case study allowed for a more holistic and contextual view (Creswell, 2013) of how students wrestle and resolve with their metacognition in a large, introductory science course. Drawing on phenomenology allowed me to develop a shared meaning for how students describe and experience metacognition within this particular, bounded course. The analysis of the interviews contributed a rich description of student experience to the case study and demonstrated the complexity of student learning within a university setting.

\section{Benefits}

The use of phenomenological methods was complementary to the goal of this interpretive case study. Interpretive frameworks aim to develop meaning from understanding through the exploration of experiences and reflections of not only the research participants, but the researchers as well (Bogdan \& Biklen, 1998; Creswell, 2013). While the case study bounded and contextualized student learning and experiences within a given course, phenomenological inquiry provided the necessary means to better understand the conscious experience of students within this given context. Furthermore, as a researcher, phenomenology pushed me to continually consider the holistic, personal, and contextual complexities of student experiences. This experience was initially compartmentalized by data collection method (survey responses, student reflections, classroom observations, interviews), but the triangulation of the data within an interpretive framework helped me to build a bigger picture of the catalysts influencing students' metacognition and learning.

\section{Challenges}

Engaging in mixed method research is complex given both the complementary and competing paradigms and epistemologies of quantitative and qualitative work (Sale, Lohfeld, \& Brazil, 2002). There is potential that the design, triangulation, and interpretation of data from multiple frameworks can limit the overall credibility of the research. Within this case, adopting an interpretive framework aligned with my perspective of learning as fluid, ongoing, and complex, but the statistical analysis of survey data 
often competed with this framework. Throughout the design, analysis, and dissemination of this research, there was a constant need to acknowledge and clarify how my own positionality and epistemology as a researcher influenced the research questions being asked and the interpretation of the data.

While phenomenology, and the use of in-depth interviews, provided a much-needed lens into the lived experiences of students, the entirety or richness of these experiences may have been overshadowed by additional methods and epistemologies. There was a push-pull relationship between gaining a broad perspective (via surveying and observing a large group of students) and/or gaining a richer, more specific perspective with fewer students (via interviews). While the interviews were in depth, they were only a piece of the puzzle with respect to the overall experiences of students within this given course. While aspects of the lived experiences may have been overshadowed, they were necessary to provide a broader picture of student learning within the context of this particular course and to best answer the research questions of the study.

\section{DISCUSSION}

Despite the difference of researchers, participants, theoretical frameworks, and methods, both of the projects were able to successfully use phenomenology to address their research questions and appropriately analyze the data. Table 1 provides a summary of the holistic benefits and challenges that emerged during our research projects. The purpose of the table is to throw into stark relief the similarities and differences between our projects. These similarities and differences are also unique to the use of phenomenology in the studies.

Table 1. Holistic benefits and challenges in SoTL research

\begin{tabular}{|c|c|c|}
\hline PROJECT & BENEFITS & CHALLENGES \\
\hline A & $\begin{array}{l}\text { - Seek out multiple meanings in the } \\
\text { participants' experiences. } \\
\text { - Recognize the researcher as both } \\
\text { insider and outsider in the research. } \\
\text { - Interpretive phenomenology is } \\
\text { responsive to the research as it unfolds. }\end{array}$ & $\begin{array}{l}\text { - } \quad \text { Messy" methods } \\
\text { - } \quad \text { Participant pool }\end{array}$ \\
\hline B & $\begin{array}{l}\text { - Complementary to case study } \\
\text { design/methodology } \\
\text { - Embodies "lived experience" }\end{array}$ & $\begin{array}{l}\text { - Issue with competing } \\
\text { methodologies/epistemologies in mixed methods } \\
\text { research } \\
\text { - Richness of experiences may be lost }\end{array}$ \\
\hline
\end{tabular}

\section{Holistic benefits of phenomenological inquiry}

Phenomenology offers a philosophical grounding for methodology and methods that explore lived experiences. Despite the difference in the studies, we each adopted and tailored phenomenological inquiry based on the research questions we were asking. One of the benefits of phenomenological inquiry is that it gives SoTL researchers permission to adopt a flexible, adaptable approach to their specific research context and questions. Project A demonstrates how a SoTL researcher can wholly adopt phenomenology as a methodology, yet Project B exemplifies how phenomenological methods can complement other qualitative methodologies. 
Phenomenological rigor stems from its authentic relationship to a researcher's epistemology and the research questions that are being asked, and the position of participants as valued co-constructors of research findings. As a methodology, phenomenology in SoTL research emphasizes the experiences of the participants. For example, van Manen's (1997) methodology encourages multiple opportunities for the interviewer and the interviewee to review and discuss a co-constructed description of the phenomenon emerged. The richness of the data comes from the perspective of the participants and places them at the heart of the research. In SoTL research projects, this allows researchers to include and engage students and colleagues as partners. In this way, researchers are able to benefit from their involvement as both part of the classroom and observers of it. The position of instructor/SoTL researcher encourages iterative and ongoing engagement with the teaching and learning environment and allows opportunities for follow up and longitudinal study.

\section{Holistic challenges of phenomenological inquiry}

Because SoTL researchers are trained in many different disciplines and methodological traditions, adopting a phenomenological methodology necessitates adjusting to different approaches to research. This can be particularly challenging for scholars exploring questions or topics that differ from the epistemologies and methodologies practiced in their field of study (Sale et al., 2002). Simply accepting or adopting a methodology can limit the researcher's ability to engage with and interpret the experiences of the participants. Regardless of whether the research methods are qualitative or quantitative in nature, it is imperative for SoTL scholars to acknowledge how their own assumptions, biases, and epistemologies are commensurate with the research question and then influence the design, administration, and interpretation of the research (Cresswell, 2013; Treagust et al., 2014). Within both Project A and Project B, we explicitly questioned and articulated how our roles and decisions as educators and researchers influenced the overall research project to better inform ourselves and the readers about the limitations and complexity of our qualitative and mixed method work. A process that may or may not be the norm in particular disciplinary fields.

A phenomenological research approach, based predominantly on interviews, presents limitations. First, the methodology depends on the participants being able to clearly articulate their lived experience. As a result, the findings and conclusions are highly influenced by the population of the study and the specific time frame of the data collection. This means that, in order to focus on a rich description of lived experience, the scope of the study may miss influential factors that led up to the experience or the concomitant factors that are associated with the experience. Much phenomenological research attempts to increase the validity and reliability of the data collection and analysis by creating scholarly distance between the researcher and the researched (Creswell, 2013; Wertz et al., 2011). Although it is challenging, especially as researchers are often intricately involved in the programs they study, putting aside personal knowledge and assumptions is important in order to set aside our lived experience in favour of the participants' points of view.

There are no universal criteria to determine the trustworthiness of phenomenological research, so we suggest using Lincoln and Guba's (1985) seminal criteria for evaluating the trustworthiness of a phenomenological inquiry: credibility, transferability, dependability, and confirmability:

- Credibility refers to the faithfulness of the description of the phenomenon. The credibility of the research is demonstrated, in part, through evidence (i.e., use of the participants' words or quotations from transcripts), as detailed substantiation from 
participants provides an insider's view (Charmaz \& Mitchell, 1996).

- Transferability suggests the applicability of the results to other contexts. As a result, the researcher needs to restrict their discussion of the findings to the study's participants and should temper their generalizations when considering other participants, other contexts, or other programs.

- Dependability refers to the extent to which another researcher can follow the analytical decisions made by the researcher (Lincoln \& Guba, 1985). Therefore, the researcher must keep a detailed account of the steps in the research process to provide a detailed audit trail to describe the stages of data collection and analysis.

- Finally, the assessment of confirmability refers to the grounding of the results in the data and a logical assessment of the inferences (Lincoln \& Guba, 1985).

These are important factors to consider when ensuring the trustworthiness of a SoTL research project. In our research projects, we provide detailed descriptions of the phenomena, using the participants' words as much as possible. In this way, readers can make their own decision as to the relevance of the results outside of this study. Through transparency in ethics, transcription, and data analysis (Tracy, 2010), phenomenological research sincerely reflects the focus on participants' lived experience. Referring to and adopting these aspects of trustworthiness helped us to better conduct credible and rigorous SoTL work.

\section{CONCLUSION}

Phenomenological research is rigorous, well supported, and adds credence to the field of SoTL generally. Utilizing phenomenological methodology for SoTL and other teaching and learning research contributes literature informed research to the public discourse around practices in institutions and focuses specifically on the experiences of faculty, staff, and students in higher education. For those interested in beginning phenomenological research, we recommend in particular Adams \& van Manen, 2008; Creswell, 2013; Creswell \& Poth, 2018; Laverty, 2003; and van Manen, 1997. Phenomenological inquiry contributes to the practice of SoTL by offering a methodology that is accessible to novice and experienced SoTL scholars and centrally frames the experience of participants. Importantly, phenomenology has motivated us to tell our stories of SoTL research and within those, to share the stories that faculty and students shared with us.

\section{ACKNOWLEDGMENTS}

The authors thank the participants at ISSOTL 2016 who offered support and valuable feedback for this article and recognize the important contribution of the journal reviewers.

\section{Andrea S. Webb is an Instructor 1 in the Faculty of Education at the University of British Columbia (CAN). Her work focuses on developing educational leadership in the Scholarship of Teaching and Learning.}

Ashley J. Welsh is a Faculty Liaison (Faculty of Science) cross-appointed between the Science Centre for Learning and Teaching and the Centre for Teaching, Learning, and Technology at the University of British Columbia (CAN). She advises and supports faculty and graduate students with the development and evaluation of teaching and learning enhancement projects. 


\section{REFERENCES}

Adams, C., \& van Manen, M. (2008). Phenomenology. In L. M. Given (Ed.), The Sage Encyclopedia of Qualitative Research Methods (Vol. 2) (pp. 614-619). Thousand Oaks, CA: Sage. http://dx.doi.org/10.4135/9781412963909.n317

Anderson, D., Nashon, S. M., \& Thomas, G. P. (2009). Evolution of research methods for probing and understanding metacognition. Research in Science Education, 39(2), 181-195. https://doi.org/10.1007/s11165-007-9078-1

Boekaerts, M., \& Corno, L. (2005). Self-regulation in the classroom: A perspective on assessment and intervention. Applied Psychology: An international review, 54(2), 199-231. https://doi.org/10.1111/j.14640597.2005.00205.x

Bogdan, R. C., \& Biklen, S. K. (1998). Qualitative research for education: An introduction to theory and methods, 3rd. ed. Needham Heights, MA: Allyn \& Bacon.

Charmaz, K., \& Mitchell, R. (1996). The myth of silent authorship: Self, substance, and style in ethnographic writing. Symbolic Interaction, 19(4), 285-302. https://doi.org/10.1525/si.1996.19.4.285

Creswell, J. W. (2009). Research design: Qualitative, quantitative, and mixed methods approaches (3rd ed.). Thousand Oaks, CA: Sage.

Creswell, J. W. (2013). Qualitative inquiry and research design: Choosing among five approaches (3rd ed.). Thousand Oaks, CA: Sage.

Creswell, J. W. \& Poth, C. N. (2018). Qualitative inquiry and research design: Choosing among five approaches (4th ed.). Thousand Oaks, CA: Sage.

Dall'Alba, G. (2009). Phenomenology and education: An introduction. Educational Philosophy and Theory, 41(1), 79.https://doi.org/10.1111/j.1469-5812.2008.00479.x

Danielson, M. A. (2012). SoTL as a generative heuristic methodology for building learning communities. International Journal for the Scholarship of Teaching and Learning, 6(2), article 4. https://doi.org/10.20429/ijsotl.2012.060204

Denzin, N. K. \& Lincoln, Y. S. (2011). The Sage handbook of qualitative research (4th ed.). Thousand Oaks, CA: Sage.

Flavell, J. H. (1979). Metacognition and cognition monitoring: A new area of cognitive-developmental inquiry. American Psychologist, 34, 906-911.http://dx.doi.org/10.1037/0003-066X.34.10.906

Giorgi, A. P., \& Giorgi, B. M. (2003). The descriptive phenomenological psychological method. In P. M. Camic, J. E. Rhodes, \& L. Yardley (Eds.), Qualitative research in psychology: Expanding perspectives in methodology and design (pp. 243-273). Washington, DC: American Psychological Association.

Hubball, H. T. \& Clarke, A. (2010). Diverse methodological approaches and considerations for SoTL in higher education. Canadian Journal for the Scholarship of Teaching and Learning, 1(1). http://dx.doi.org/10.5206/cjsotl-rcacea.2010.1.2

Hubball, H. T., Clarke, A. C., Webb, A., \& Johnson, B. (2015). Developing institutional leadership for the scholarship of teaching and learning: Lessons learned with senior educational leaders in multinational researchintensive university contexts. International Journal of University Teaching and Faculty Development, 4(4), 237-253.

Huber, M.T. (2010). Editorial: CASTL has concluded. Long live the scholarship of teaching and learning. Arts and Humanities in Higher Education, 9(1), 5-8. https://journals.sagepub.com/doi/pdf/10.1177/1474022209357660

Hutchings, P. (2007). Theory: The elephant in the scholarship of teaching and learning room. International Journal for the Scholarship of Teaching and Learning, 1(1), article 2. https://doi.org/10.20429/ijsotl.2007.010102

Kreber, C. (2007). What's it really all about? The scholarship of teaching and learning as an authentic practice. International Journal for the Scholarship of Teaching and Learning, 1(1), article 3. Retrieved from https://digitalcommons.georgiasouthern.edu/ij-sotl/vol1/iss1/3/

Laverty, S. M. (2003). Hermeneutic phenomenology and phenomenology: A comparison of historical and methodological considerations. International Journal of Qualitative Methods, 2(3), 21-35. https://doi.org/10.1177/160940690300200303

Lincoln, Y. S., \& Guba, E. G. (1985). Naturalistic inquiry. Beverly Hills, CA: Sage Publications. 
Lopez, K. A. \& Willis, D. G. (2004). Descriptive versus interpretive phenomenology: Their contributions to nursing knowledge. Qualitative Health Research, 14(5), 726-735.https://doi.org/10.1177/1049732304263638

Mertens, D. (1998). Research methods in education and psychology: Integrating diversity with quantitative and qualitative approaches. Thousand Oaks: Sage.

Meyer, J. H. F., \& Land, R. (2003). Threshold concepts and troublesome knowledge: Linkages to ways of thinking and practising within the disciplines. In C. Rust (Ed.), Improving student learning theory and practice-Ten years on: Proceedings of the 2002 10th International Symposium Improving Student Learning (pp. 412-424). Oxford, UK: Oxford Centre for Staff and Learning Development.

Meyer, J. H. F., \& Land, R. (2005). Threshold concepts and troublesome knowledge (2): Epistemological considerations and a conceptual framework for teaching and learning. HigherEducation, 49(3), 373388. https://doi.org/10.1007/s10734-004-6779-5

Meyer, J. H. F., \& Land, R. (2006). Threshold concepts and troublesome knowledge: An introduction. In J. H. F. Meyer \& R. Land (Eds.), Overcoming barriers to student understanding: Threshold concepts and troublesome knowledge (pp. 3-18). London, UK: Routledge.

Moran, D. (2000). Introduction to phenomenology. New York, NY: Routledge.

Moran, D. (2013). "Let's look at it objectively": Why phenomenology cannot be naturalized. Royal Institute of Philosophy Supplement, 72, 89-115.https://doi.org/10.1017/S1358246113000064

Østergaard, E., Dahlin, B., \& Hugo, A. (2008). Doing phenomenology in science education: A research review. Studies in Science Education, 44(2), 93-121. https://www.tandfonline.com/doi/abs/10.1080/03057260802264081

Parker, J. (2009). Theory of SoTL: Translating international perspectives. In J. Fanghanel, N. Rege Colet, \& D. Bernstein (Eds.), London Scholarship of Teaching and Learning 7th International Conference (2008) proceedings, Vol. 4. London, UK: City University London.

Sale, J. E. M., Lohfeld, L. H., \& Brazil, K. (2002). Revisiting the quantitative qualitative debate: Implications for mixed-methods research. Quality \& Quantity, 36(1), 43-53.https://doi.org/10.1023/A:1014301607592

Smith, D. W. (2006). Phenomenology. In L. Nadel (Ed.), Encyclopedia of cognitive science. https://doi.org/10.1002/0470018860.s00153

Stake, R. E. (1995). The art of case study research. Thousand Oaks, CA: Sage.

Stake, R. E. (1997). Case study methods in educational research: Seeking sweet water. In G. Glass \& R. M. Jaeger (Eds.), Complementary Methods for Research in Education (pp. 401-427). Washington, DC: American Educational Research Association.

Stierer, B., \& Antoniou, M. (2004). Are there distinctive methodologies for pedagogic research in higher education? Teaching in Higher Education, 9(3), 275-85. https://doi.org/10.1080/1356251042000216606

Tracy, S. (2010). Qualitative quality: Eight "big tent" criteria for excellent qualitative research. Qualitative Inquiry, 16(10), 837-851. https://doi.org/10.1177/1077800410383121

Treagust, D. F., Won, M., \& Duit, R. (2014). Paradigms in science education. In N. G. Lederman \& S. K. Abell (Eds.), Handbook of research on science education (Vol. 2) (pp. 3-17). New York: Routledge.

van Manen, M. (1997). Researching lived experience: Human science for an action sensitive pedagogy (2nd ed.) London, ON: Althouse Press.

Webb, A. S. (2015). Threshold concepts in the scholarship of teaching and learning: A phenomenological study of educational leaders in a Canadian research-intensive university (Unpublished doctoral dissertation). University of British Columbia. Retrieved from https://open.library.ubc.ca/clRcle/collections/24/items/1.0167152

Welsh, A. J. (2015). Investigating undergraduate students' metacognitive transformations in an introductory organic chemistry course (Unpublished doctoral dissertation). University of British Columbia. Retrieved from https://open.library.ubc.ca/cIRcle/collections/ubctheses/24/items/1.0167135

Wertz, F. J., Charmaz, K., McMullen, L M., Josselson, R., Anderson, R., \& McSpadden, E. (2011). Five ways of doing qualitative analysis: Phenomenological psychology, grounded theory, discourse analysis, narrative research, and intuitive inquiry. New York, NY: Guilford Press.

Yin, R. K. (2009). Case study research:Design and method (4th ed.). Thousand Oaks, CA: Sage. 


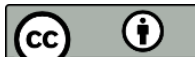

Copyright for the content of articles published in Teaching \& Learning Inquiry resides with the authors, and copyright for the publication layout resides with the journal. These copyright holders have agreed that this article should be available on open access under a Creative Commons Attribution License 4.0 International (https://creativecommons.org/licenses/by/4.0). The only constraint on reproduction and distribution, and the only role for copyright in this domain, should be to give authors control over the integrity of their work and the right to be properly acknowledged and cited, and to cite Teaching \& Learning Inquiry as the original place of publication. Readers are free to share these materials-as long as appropriate credit is given, a link to the license is provided, and any changes are indicated. 